Quim. Nova, Vol. 31, No. 3, 574-578, 2008

\title{
DETERMINATION OF ETORICOXIB IN HUMAN PLASMA USING AUTOMATED ON-LINE SOLID-PHASE EXTRACTION COUPLED WITH LC-APCI/MS/MS
}

\author{
Sérgio Luiz Dalmora*, Liberato Brum Junior, Ricardo Machado Ferretto, Paulo Renato de Oliveira, Thiago Barth \\ and Maximiliano da Silva Sangoi \\ Departamento de Farmácia Industrial, Centro de Ciências da Saúde, Universidade Federal de Santa Maria, 97105-900 Santa \\ Maria-RS, Brazil
}

Recebido em 24/4/07; aceito em 20/9/07; publicado na web em 26/2/08

\begin{abstract}
A liquid chromatography-tandem mass spectrometry method with atmospheric pressure chemical ionization (LC-APCI/MS/MS) was validated for the determination of etoricoxib in human plasma using antipyrin as internal standard, followed by on-line solidphase extraction. The method was performed on a Luna $\mathrm{C}_{18}$ column and the mobile phase consisted of acetonitrile:water (95:5, v/ v)/ammonium acetate $(\mathrm{pH} 4.0 ; 10 \mathrm{mM})$, run at a flow rate of $0.6 \mathrm{~mL} / \mathrm{min}$. The method was linear in the range of $1-5000 \mathrm{ng} / \mathrm{mL}$ $\left(r^{2}>0.99\right)$. The lower limit of quantitation was $1 \mathrm{ng} / \mathrm{mL}$. The recoveries were within $93.72-96.18 \%$. Moreover, method validation demonstrated acceptable results for the precision, accuracy and stability studies.
\end{abstract}

Keywords: etoricoxib; LC-APCI/MS/MS; on-line solid-phase extraction.

\section{INTRODUCTION}

Etoricoxib (5-chloro-6'-methyl-3-[4-(methylsulfonyl)phenyl]$2,3^{\prime}$-bipyridine) represents a second-generation of cycloxygenase-2 (COX-2) inhibitors that has been developed for the treatment of many inflammatory diseases such as rheumatoid arthritis, osteoarthritis, pain relief and acute gout, causing fewer gastrointestinal complications than conventional non-steroidal antiinflammatory drugs. ${ }^{1-3}$ Etoricoxib is well orally absorbed, and following $120 \mathrm{mg}$ single daily dosage to fasted adults, the peak plasma concentration (geometric mean $C_{\max }=3600 \mathrm{ng} / \mathrm{mL}$ ) was observed at approximately $\left.1 \mathrm{~h}\left(t_{\max }\right)\right)^{4-6}$

An analytical high performance liquid chromatography (HPLC) method with photochemical cyclisation and fluorescence detection for the quantitation of etoricoxib in human plasma and urine was published using a structural analogue as internal standard and offline solid-phase extraction (SPE). ${ }^{7}$ A liquid chromatography-tandem mass spectrometry (LC-MS/MS) method with atmospheric pressure chemical ionization (APCI) was validated over the concentration range of $0.5-250 \mathrm{ng} / \mathrm{mL}$ for the determination of etoricoxib in human plasma with a stable isotope as internal standard, and the run time of 8 min. ${ }^{8}$ The LC-MS/MS method with electrospray ionization (ESI) for the determination of etoricoxib in human plasma, after extraction by off-line SPE was also developed over the concentration range of $0.2-200 \mathrm{ng} / \mathrm{mL} .{ }^{9}$ A liquid chromatography (LC) coupled with to ion trap mass spectrometry and APCI for quantitation of both etoricoxib and valdecoxib in human plasma was also performed in the linear range of $10-2500 \mathrm{ng} / \mathrm{mL} .^{10}$ The LC method for the quantitation of etoricoxib in human plasma was validated with the run time of 10 min. ${ }^{11}$ The reversed phase LC method was validated for the determination of etoricoxib in pharmaceutical dosage forms and compared to the LC-MS/MS method validated with detection by ESI, applied also for the determination of etoricoxib in spiked human plasma. ${ }^{12,13}$

The matrix ion suppression requires that the majority of the

*e-mail: sdalmora@terra.com.br biological matrix constituents being removed prior to LC-MS/MS analysis of the analyte of interest making sample pre-treatment a time consuming step in the development of LC-MS/MS procedure. This can be performed using either liquid-liquid extraction (LLE) or traditional off-line SPE, which needs either relatively large volumes of plasma (typically 1-2 mL) or organic solvents (2-4 mL) for the elution of the analyte from the solid phase. Apart from full automation, the state-of-the-art for on-line SPE also provides high precision and sensitivity and a higher sample throughput as compared to LLE or off-line SPE. ${ }^{14,15}$

The aim of the present work was to develop and validate a sensitive and automated high throughput on-line SPE-LC-MS/MS method for the determination of etoricoxib in human plasma, improving the current published procedures, in order to support human clinical studies.

\section{EXPERIMENTAL}

\section{Chemical and reagents}

Etoricoxib reference substance was generously supplied by Merck Research Laboratories (Rahway, USA) and antipyrin, as internal standard (IS), was purchased from Sigma (St Louis, MO, USA). HPLC-grade acetonitrile, methanol and formic and acetic acid were purchased from Tedia (Fairfield, USA). Ammonium acetate was purchased from Merck (Darmstadt, Germany). All chemicals used were of pharmaceutical or special analytical grade. For all the analyses, ultrapure water was purified using an Elix 3 coupled to a Milli-Q Gradient A10 system (Millipore, Bedford, MA, USA).

\section{Preparation of stock solutions}

The stock solution of etoricoxib was prepared by weighing 10 $\mathrm{mg}$ of reference material into a $10 \mathrm{~mL}$ volumetric flask and diluting to volume with acetonitrile, obtaining a concentration of $1 \mathrm{mg} / \mathrm{mL}$. Antipyrin stock solution was also made at a final concentration of 1 $\mathrm{mg} / \mathrm{mL}$ using acetonitrile. The prepared stock solutions were stored at $2-8{ }^{\circ} \mathrm{C}$ protected from light. 


\section{Preparation of calibration reference and quality control samples}

The stock solution of etoricoxib was diluted with acetonitrile to obtain calibration reference solutions with the concentrations of 10000, 1000, 100 and $10 \mathrm{ng} / \mathrm{mL}$. The corresponding volume taken of the reference solutions were evaporated under nitrogen stream while immersed in a $40{ }^{\circ} \mathrm{C}$ water bath, and the residues reconstituted in $0.5 \mathrm{~mL}$ of blank plasma to prepare the calibration reference containing from 1 to $5000 \mathrm{ng} / \mathrm{mL}(1,10,100,500,1000,2000$ and $5000 \mathrm{ng} / \mathrm{mL}$ ). The quality control (QC) samples were prepared in pooled plasma, with the concentrations of 3 (low), 2500 (medium) and $4000 \mathrm{ng} / \mathrm{mL}$ (high), and then divided in aliquots that were stored at $-80{ }^{\circ} \mathrm{C}$ until analysis.

\section{Sample preparation}

A total of $500 \mu \mathrm{L}$ of the plasma was transferred to a glass tube, followed by addition of $50 \mu \mathrm{L}$ of internal standard solution ( $250 \mathrm{ng} /$ $\mathrm{mL}$ of antypirin in acetonitrile). All samples were mixed by vortex agitation for 30 seconds and transferred to autosampler vials. Samples were then injected onto the system.

\section{Cartridges and on-line SPE system}

The following cartridges $(10 \times 2 \mathrm{~mm}$ i.d.) with the different particles size were used for the development of the on-line solidphase extraction: HySphere CN, $8 \mu \mathrm{m}$; HySphere $\mathrm{C}_{2}, 8 \mu \mathrm{m}$; HySphere $\mathrm{C}_{8}, 8 \mu \mathrm{m}$; HySphere $\mathrm{C}_{8}(\mathrm{EC}), 8 \mu \mathrm{m}$; HySphere $\mathrm{C}_{18}, 8 \mu \mathrm{m}$; HySphere $\mathrm{C}_{18} \mathrm{HD}, 7 \mu \mathrm{m}$; HySphere Resin GP, 10-12 $\mu \mathrm{m}$; HySphere Resin SH, 15-25 $\mu \mathrm{m}$; BondElut $\mathrm{C}_{18}, 40-90 \mu \mathrm{m}$ and BondElut $\mathrm{C}_{8}, 40-90 \mu \mathrm{m}$.

On-line SPE system Prospekt-2 (Spark Holland, Emmem, The Netherlands), consisted of an automated cartridge exchange (ACE) module for disposable cartridge exchange; high-pressure dispenser (HPD) module for handling of solvents, which transports the liquids by the $2 \mathrm{~mL}$ high pressure syringe (up to $300 \mathrm{bar}$ ) and the triathlon autosampler. The entire system was operated by SparkLink ${ }^{\mathrm{TM}}$ software program (V 2.30. Spark, Holland).

The injection and the extraction were completely automated using Prospekt-2 system and the method developed consisted of the following steps: the cartridge was solvated with $1 \mathrm{~mL}$ of methanol at $5 \mathrm{~mL} / \mathrm{min}$ and equilibrated with $1 \mathrm{~mL}$ of water at same flow rate. Following the injection of $20 \mu \mathrm{L}$ of the plasma sample into the cartridge, $750 \mu \mathrm{L}$ of water at $2 \mathrm{~mL} / \mathrm{min}$ were eluted, to retain etoricoxib and antipyrin, and waste plasma proteins. The cartridge was washed with $1 \mathrm{~mL}$ of water:methanol $(95: 5$, v/v) at $2 \mathrm{~mL} / \mathrm{min}$, and then, eluted with mobile phase at $0.6 \mathrm{~mL} / \mathrm{min}$ for $1 \mathrm{~min}$ to the analytical column and hence to MS/MS. After the elution and during LC-MS/MS run, the cartridge was washed with $2 \mathrm{~mL}$ of acetonitrile:water $(50: 50, \mathrm{v} / \mathrm{v})$ at a flow rate of $2 \mathrm{~mL} / \mathrm{min}$. The autosampler was programmed to perform a wash of the needle with $500 \mu \mathrm{L}$ of acetonitrile: $2 \%$ formic acid $(50: 50, \mathrm{v} / \mathrm{v})$, to reduce carryover, including one extra-wash step.

\section{LC-MS/MS conditions}

The LC-MS/MS method was performed on a Shimadzu LC system (Shimadzu, Kyoto, Japan) equipped with a SCL-10A $\mathrm{vp}_{\mathrm{vP}}$ system controller, LC-10 $\mathrm{AD}_{\mathrm{VP}}$ pump, DGU-14A degasser, and CTO-10 $\mathrm{AD}_{\mathrm{VP}}$ column oven. A triathlon autosampler (Spark, Emmen, Holland) was used. The experiments were carried out on a reversed phase Phenomenex (Torrance, USA) Luna $\mathrm{C}_{18}$ column (50 x $3.0 \mathrm{~mm}$ i.d.), with a particle size of $3 \mu \mathrm{m}$ and pore size of $100 \AA$ ). A security guard holder $(4.0 \times 3.0 \mathrm{~mm}$ i.d.) was used to protect the analytical column. The LC system was operated isocratically at controlled temperature $\left(25^{\circ} \mathrm{C}\right)$ using a mobile phase of acetonitrile:water (95:5, $\mathrm{v} / \mathrm{v}) /$ ammonium acetate $(\mathrm{pH} 4.0 ; 10 \mathrm{mM})$. This was filtered through a $0.45 \mu \mathrm{m}$ membrane filter (Millipore, Bedford, MA, USA) and run at a flow rate of $0.6 \mathrm{~mL} / \mathrm{min}$. The injection volume was $20 \mu \mathrm{L}$ for both reference and samples. The triple quadrupole mass spectrometer (Micromass, Manchester, UK), model Quattro LC, equipped with an APCI source using a crossflow counter electrode run in positive mode (APCI+), was set up in multiple reaction monitoring (MRM) mode, monitoring the transitions 359.6>280.1 and 189.6>172, for etoricoxib and IS, respectively. For the optimization of mass spectrometer conditions, a mixed reference solution $(1000 \mathrm{ng} / \mathrm{mL})$ containing etoricoxib and IS was directly introduced and the following parameters were selected: Corona voltage, extractor voltage, RF lens voltage, source temperature and APCI probe temperature were $2.5 \mathrm{kV}, 5 \mathrm{~V}, 0.5 \mathrm{~V}, 120$ and $450{ }^{\circ} \mathrm{C}$, respectively. The cone voltage was 65 and $30 \mathrm{~V}$ and the collision energy 35 and $10 \mathrm{eV}$, respectively for etoricoxib and IS. Data acquisition and analysis were performed using the software Masslynx (v 3.5).

\section{Validation of the bioanalytical method}

The method was validated by the determination of the following parameters: matrix effects, specificity, linearity, recovery, accuracy, precision, lower limit of quantitation (LLOQ) and stability studies, according to the FDA guidelines. ${ }^{16}$

To evaluate the matrix effects, three replicates of low, medium and high quality control samples were spiked, each one, with six samples of blank human plasma from different sources. The mean peak areas of each quality control were compared to the mean peak areas of the neat reference (etoricoxib and IS dried and reconstituted in acetonitrile:water, 50:50, v/v) at the same concentrations.

In order to determine the linearity of the method, the calibration curves were constructed from a blank plasma, blank plasma spiked with IS and seven concentrations of etoricoxib including the LLOQ, ranging from 1 to $5000 \mathrm{ng} / \mathrm{mL}$. The peak area ratio of the drug to the IS against the respective reference concentrations was used for plotting the graph and the linearity evaluated by a weighted $(1 / x)$ least squares regression analysis. The acceptance criteria for each calculated reference concentration was not more than $15 \%$ deviation from the nominal value, except for the LLOQ, which was set at $20 \%$. The lowest reference concentration on the calibration curve should be selected as at least five times the response compared to blank response and the analyte peak (response), identifiable, discrete and reproducible with a precision of $20 \%$ and accuracy of $80-120 \%$.

To evaluate the inter-day precision and accuracy, the quality control samples were analysed together with one independent calibration reference curve for 3 days, while intra-day precision and accuracy were evaluated the analysis of validation control samples at three different concentrations in six replicates in the same day. Inter- and intra-day precision was expressed as relative standard deviation (RSD). The accuracy was expressed as the percent ratio between the experimental concentration and the nominal concentration for each sample. The evaluation of precision was based on the criteria ${ }^{16}$ that the deviation of each concentration level should be within $\pm 15 \%$, except for the LLOQ, for which it should be within $\pm 20 \%$. Similarly for accuracy, the mean value should not deviate by $\pm 15 \%$ of the nominal concentration except the LLOQ where it should not deviate by $\pm 20 \%$ of the nominal concentration.

The analytical recovery was calculated by comparing chromatographic peak areas from un-extracted reference samples and from extracted reference samples at three different 
concentrations $(3,2500$ and $4000 \mathrm{ng} / \mathrm{mL})$ for the etoricoxib and $100 \mathrm{ng} / \mathrm{mL}$ for the IS. The specificity was assessed using six blank human plasma samples, randomly selected, from different sources (including haemolysed and lipemic plasma), that were subjected to the extraction procedure and chromatographed to determine the extent to which endogenous plasma components could interfere in the analysis of etoricoxib or the IS. The results were compared to a solution containing $1 \mathrm{ng} / \mathrm{mL}$ of etoricoxib.

For the stability studies, the concentration of etoricoxib after each storage period was determined at low, medium and high QC samples $(n=3)$, and related to the initial concentration as zero cycle (samples that were freshly prepared and processed immediately). The samples were considered stable if the deviation (expressed as percentage bias) from the zero cycle was within \pm $15 \%$.

The freeze-thaw stability of etoricoxib was determined over three freeze-thaw cycles within 3 days. In each cycle, the frozen plasma samples were thawed at room temperature for $2 \mathrm{~h}$ and refrozen for $24 \mathrm{~h}$, and then analysed. The short-term stability was evaluated using three aliquots of the unprocessed QC samples kept at room temperature $\left(25 \pm 5^{\circ} \mathrm{C}\right)$ for $12 \mathrm{~h}$ and then analysed. For the longterm stability the three aliquots of the QC samples were frozen at $80{ }^{\circ} \mathrm{C}$ for 60 days, and then analysed. The processed sample stability was tested using six aliquots each one of the QC samples, processed and placed into the autosampler at room temperature. Three sets were analysed after $24 \mathrm{~h}$ and three sets after $48 \mathrm{~h}$.

\section{RESULTS AND DISCUSSION}

During the SPE method development different types of cartridges, and different extraction and elution conditions were tested. Solvents and mixtures were also evaluated, including acetonitrile, methanol and formic acid. The best chromatographic separation efficiency, MS/MS sensitivity and recovery for etoricoxib and IS, were obtained using the HySphere $\mathrm{C}_{18} \mathrm{HD}$ cartridge. In the optimized condition achieved, the cartridge was solvated, equilibrated and washed using methanol, water and water:methanol $(95: 5, v / v)$, respectively. The total cycle time of the Prospekt-2 method was $4 \mathrm{~min}$. Comparing to the traditional off-line solid-phase and liquid-liquid extractions coupled with LC-MS/MS, the proposed method requires smaller amounts of plasma, does not need concentration of extracts before injection, and requires a shorter sample preparation time. When all the steps of the analytical procedure are taken into account (SPE and LC-MS/MS), the total analysis time was 6 minutes, an important advantage when large amount of samples need to be quantified, as it is, for example in clinical and pharmacokinetic studies.

The chromatographic conditions were studied and the best signal achieved with the mobile phase selected for the analysis, performed using a short $(50 \mathrm{~mm}) \mathrm{C}_{18}$ analytical column, which is convenient for high throughput of samples. The low flow rate and the short run time (2 min) resulted, comparatively, in lower consume of solvents with a better cost-effective relation.

The APCI was used as the LC-MS/MS interface, which is less susceptible to analyte-ion suppression compared to the ESI technique. The mass spectrometric response of the analyte and the IS were measured by using selected MRM mode, in which, a set of precursor ion/product pairs was monitored. The specificity is much better than that obtained with selected ion monitoring (SIM). The MS/MS transition 359.6>280.1 and 189.6>172 were selected for the etoricoxib and IS, respectively. The product ion scan, of etoricoxib and IS, and the fragments of etoricoxib are illustrated in Figure 1.

Matrix effects were examined and the relative standard deviation
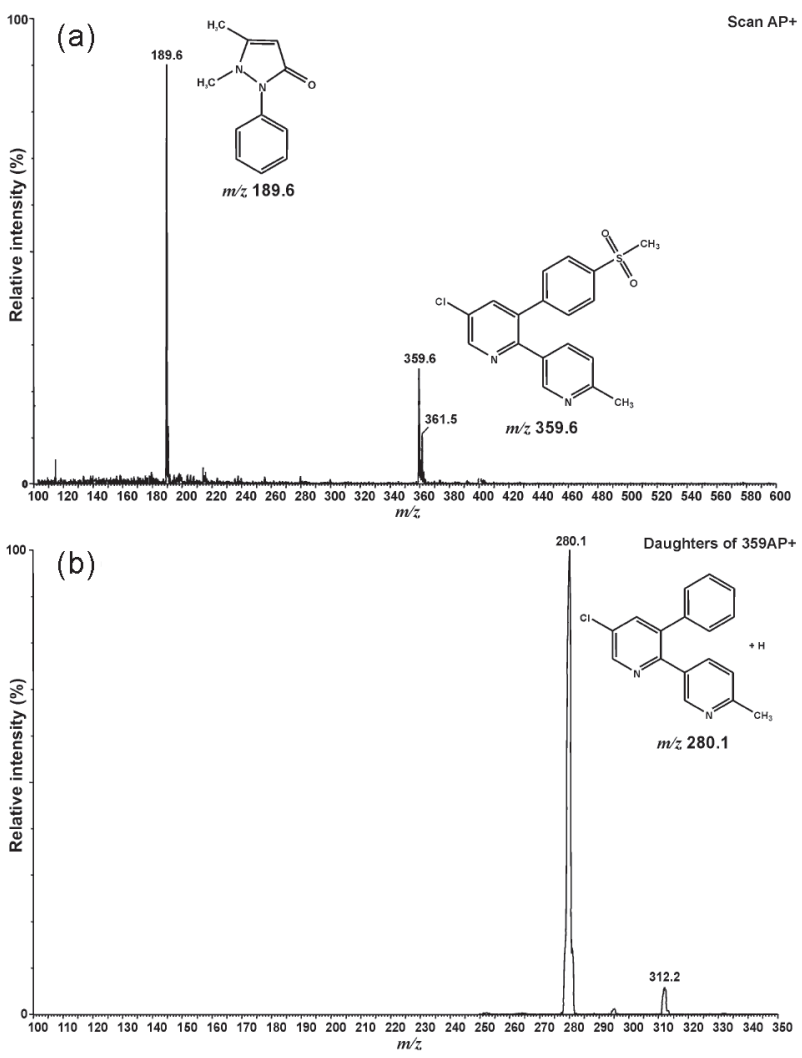

Figure 1. (a) Mass spectra and chemical structures of etoricoxib and antipyrin (internal standard) obtained by positive atmospheric pressure chemical ionization (APCI+); (b) Product ion scan of etoricoxib (m/z 359.6) and suggested structure of this fragment

(RSD) of the mean peak areas of etoricoxib and IS were $<6.26 \%$, indicating low difference in ionization efficiency using different plasma samples. Besides, the results were higher than $93.24 \%$, suggesting that the ion suppression by endogenous components was not interfering in the repeatability of the method.

The linearity determined by six determinations of the concentrations in the range of $1-5000 \mathrm{ng} / \mathrm{mL}$ gave the determination coefficient $\left(r^{2}>0.99, y=0.28 \pm 0.0005 x+0.08 \pm 0.03\right.$, where, $\mathrm{x}$ is concentration and $\mathrm{y}$ is the peak area ratio of the drug to the IS) indicating significant linearity of the calibration curve for the method. For each standard concentration calculated, the RSD values obtained were lower than $5.25 \%$ deviation from the nominal value (Table 1 ).

Table 1. Results of the standard curve for the determination of etoricoxib in human plasma

\begin{tabular}{lccc}
\hline $\begin{array}{l}\text { Spiking plasma } \\
\text { concentration } \\
(\mathrm{ng} / \mathrm{mL})\end{array}$ & $\begin{array}{c}\text { Mean concentration } \\
\text { found } \\
(\mathrm{ng} / \mathrm{mL})^{\mathrm{a}}\end{array}$ & $\begin{array}{c}\text { RSD } \\
(\%)\end{array}$ & $\begin{array}{c}\text { Accuracy } \\
(\%)\end{array}$ \\
\hline 1 & 1.06 & 5.25 & 106 \\
10 & 10.11 & 4.86 & 101.1 \\
100 & 103.17 & 3.54 & 103.17 \\
500 & 498.32 & 2.46 & 99.06 \\
1000 & 1040.68 & 2.74 & 104.07 \\
2000 & 2029.56 & 2.45 & 101.48 \\
5000 & 5242.36 & 1.97 & 104.84 \\
\hline
\end{tabular}

${ }^{a}$ Mean of six replicates

The LLOQ evaluated in an experimental assay, with the precision 
of $5.25 \%$ and accuracy of $106 \%$, was found to be $1 \mathrm{ng} / \mathrm{mL}$.

The coupling of LC with MS/MS detection showed high specificity because only the ions derived from the analytes of interest were monitored and the comparison of the chromatograms of the blank and spiked human plasma $(1 \mathrm{ng} / \mathrm{mL})$ indicated that no interferences were detected from endogenous substances. A typical chromatogram obtained by the proposed LC-MS/MS method, with the resolution of the symmetrical peak corresponding to etoricoxib and antipyrin, is shown in Figure 2. The low retention times of 0.75 and $0.70 \mathrm{~min}$ allow a rapid determination of the drug, which is an important advantage for the routine analysis.

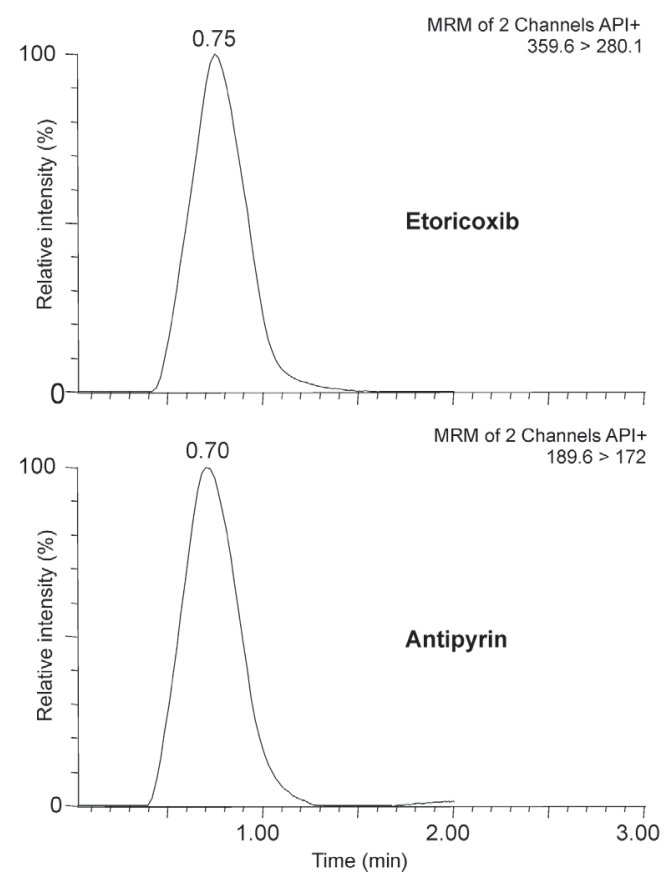

Figure 2. Representative LC-APCI/MS/MS chromatogram of plasma spiked with $3 \mathrm{ng} / \mathrm{mL}$ of etoricoxib and $25 \mathrm{ng} / \mathrm{mL}$ of antipyrin (internal standard)

Solid-phase extraction procedures were reported to extract the etoricoxib from plasma with recoveries $<90 \%$. $^{7,9}$ The liquid-liquid extraction also described in the literature showed recoveries of etoricoxib in human plasma of $96.09,82.9$ and $76.1 \%$, respectively. ${ }^{10,11}$ The proposed SPE extraction method developed and optimized, enabled high mean recoveries of etoricoxib (94.92\%) and IS $(92.20 \%)$, confirming the suitability of the method (Table 2). In the method development significant carry-over problems were found, and the introduction of an extra-wash step, reduced to a negligible effect (about 0.06\%) after the injection of the high QC, followed by the blank plasma extract.

Table 2. Recovery of etoricoxib and antipyrin after the extraction procedure

\begin{tabular}{|c|c|c|}
\hline \multirow{2}{*}{$\begin{array}{l}\text { Etoricoxib concentration } \\
(\mathrm{ng} / \mathrm{mL})\end{array}$} & \multicolumn{2}{|c|}{$\%$ Recovery (mean \pm RSD $\%$ ) } \\
\hline & Etoricoxib $^{\mathrm{a}}$ & Antipyrin ${ }^{a}$ \\
\hline 3 & $94.87 \pm 5.26$ & $92.51 \pm 6.19$ \\
\hline 2500 & $93.72 \pm 3.94$ & $90.87 \pm 4.92$ \\
\hline 4000 & $96.18 \pm 4.11$ & $93.23 \pm 5.2$ \\
\hline
\end{tabular}

${ }^{\mathrm{a}}$ Mean of six replicates

The intra-day accuracy of the method was between 100.23 and $104.66 \%$ with a precision of $4.15-5.87 \%$ (Table 3 ). The inter-day accuracy was between 97.53 and $103.00 \%$ with a RSD of 2.89$3.97 \%$ (Table 4). The data show that the method possesses suitable repeatability and reproducibility.

Table 3. Intra-day precision and accuracy for the determination of etoricoxib in human plasma

\begin{tabular}{lccc}
\hline $\begin{array}{l}\text { Spiking plasma } \\
\text { concentration } \\
(\mathrm{ng} / \mathrm{mL})\end{array}$ & $\begin{array}{c}\text { Mean concentration } \\
\text { found } \\
(\mathrm{ng} / \mathrm{mL})^{\mathrm{a}}\end{array}$ & $\begin{array}{c}\text { RSD } \\
(\%)\end{array}$ & $\begin{array}{c}\text { Accuracy } \\
(\%)\end{array}$ \\
\hline 3 & 3.14 & 5.87 & 104.66 \\
2500 & 2537.75 & 4.15 & 101.51 \\
4000 & 4009.9 & 4.52 & 100.23 \\
\hline
\end{tabular}

${ }^{a}$ Mean of six replicates

Table 4. Inter-day precision and accuracy for the determination of etoricoxib in human plasma

\begin{tabular}{lccccc}
\hline $\begin{array}{l}\text { Spiking } \\
\text { plasma } \\
\text { concentration } \\
(\mathrm{ng} / \mathrm{mL})\end{array}$ & Day & $\begin{array}{c}\text { Mean } \\
\text { concentration } \\
\text { found } \\
(\mathrm{ng} / \mathrm{mL})^{\mathrm{a}}\end{array}$ & Mean $^{\mathrm{b}}$ & $\begin{array}{c}\text { RSD } \\
(\%)\end{array}$ & $\begin{array}{c}\text { Accuracy } \\
(\%)\end{array}$ \\
\hline 3 & 1 & 3.15 & 3.09 & 2.89 & 103 \\
& 2 & 3.27 & & & \\
2500 & 3 & 3.09 & & & \\
& 1 & 2435.74 & 2438.17 & 3.05 & 97.53 \\
& 2 & 2363.45 & & & \\
4000 & 3 & 2515.32 & & & \\
& 1 & 4020 & 4058.35 & 3.97 & 101.46 \\
& 2 & 3908.8 & & & \\
& 3 & 4216.5 & & & \\
\hline
\end{tabular}

${ }^{\mathrm{a}}$ Mean of five replicates. ${ }^{\mathrm{b}}$ Mean of three days

As shown in Table 5, the plasma samples were stable for at least 60 days at $-80{ }^{\circ} \mathrm{C}$ (long-term) and also after three freezethaw cycles without compromising their integrity. Etoricoxib was stable in neat plasma for up to $12 \mathrm{~h}$ at room temperature (shortterm), and also, after maintained in the autosampler for at least 48 $\mathrm{h}$ with an acceptable precision and accuracy.

The method was applied for the quantitative analysis of etoricoxib in human plasma, after a single oral administration of $120 \mathrm{mg}$ in a pilot study in five healthy human male volunteers. The maximum plasma concentration $\left(C_{\max }\right)$ of etoricoxib was found to be $2200 \mathrm{ng} / \mathrm{mL}$ and the time to achieve maximum plasma concentration $\left(t_{\max }\right)$ was $1 \mathrm{~h}$.

\section{CONCLUSION}

An analytical method using an on-line SPE system followed by LC-APCI/MS/MS detection was developed and validated for the determination of etoricoxib in human plasma. This method includes an automated extraction procedure, using antipyrin, a commercially available substance, as internal standard. The short sample preparation time allows a higher sample throughput compared to LLE and off-line SPE methods. The results of the validation studies show that the optimized SPE-LC-APCI/MS/MS method possesses specificity, sensitivity, linearity, precision and accuracy over the entire range of significant therapeutic plasma concentrations. 
Table 5. Summary of stability of etoricoxib in human plasma

\begin{tabular}{lcccc}
\hline Stability & $\begin{array}{c}\text { Zero } \\
\text { cycle } \\
\text { concentration } \\
(\mathrm{ng} / \mathrm{mL})^{\mathrm{a}}\end{array}$ & $\begin{array}{c}\text { Concentration } \\
\text { found after } \\
\text { storage } \\
(\mathrm{ng} / \mathrm{mL})^{\mathrm{a}}\end{array}$ & $\begin{array}{c}\text { RSD } \\
(\%)\end{array}$ & $\begin{array}{c}\text { Bias }^{\mathrm{b}} \\
(\%)\end{array}$ \\
\hline \multirow{3}{*}{ Long term } & 3.23 & 2.89 & 9.04 & -10.52 \\
& 2528.06 & 2655.28 & 3.48 & 5.03 \\
& 4069.91 & 3818.29 & 3.93 & -6.18 \\
Short term & 3.23 & 2.86 & 6.32 & -11.45 \\
& 2528.06 & 2725.22 & 1.44 & 7.8 \\
& 4069.91 & 3581.62 & 1.67 & -11.99 \\
Autosampler 24 h & 2528.06 & 2506.27 & 5.5 & -0.86 \\
& 4069.91 & 4110.22 & 6.38 & 0.99 \\
& & & & \\
Autosampler 48 h & 2528.06 & 2494.3 & 9.96 & -1.33 \\
& 4069.91 & 4117.65 & 8.75 & 1.17 \\
Three freeze-thaw & 3.23 & 2.9 & 5.31 & -10.21 \\
cycles & 2528.06 & 2662.05 & 7.38 & 5.3 \\
& 4069.91 & 4428.65 & 3.65 & 8.81 \\
\hline
\end{tabular}

${ }^{\mathrm{a}}$ Mean of three replicates. ${ }^{\mathrm{b}}$ Bias $=$ (measured concentration - nominal concentration/nominal concentration) x 100

Therefore, the proposed method can be applied to support clinical and pharmacokinetic studies in healthy human volunteers.

\section{ACKNOWLEDGMENTS}

The authors wish to thank CNPq (Conselho Nacional de Desenvolvimento Científico e Tecnológico) and Merck Research Laboratories for the support.

\section{REFERENCES}

1. Riendeau, D.; Percival, M. D.; Brideau, C.; Charleson, S.; Dubé, D.; Ethier, D.; Falgueyret, J. -P.; Friesen, R. W.; Gordon, R.; Greig, G.; Guay, J.; Mancini, J.; Ouellet, M.; Wong, E.; Xu, L.; Boyce, S.; Visco, D.; Girard, Y.; Prasit, P.; Zamboni, R.; Rodger, I. W.; Gresser, M.; Ford-Hutchinson, A. W.; Young, R. N.; Chan, C. -C.; J. Pharmacol. Exp. Ther. 2001, 296, 558.

2. Rodrigues, A. D.; Halpin, R. A.; Geer, L. A.; Cui, D.; Woolf, E. J.; Matthews, C. Z.; Gottesdiener, K. M.; Larson, P. J.; Lasseter, K. C.; Agrawal, N. G. B.; Drug Metab. Dispos. 2003, 31, 224.

3. Agrawal, N. G. B.; Matthews, C. Z.; Mazenko, R. S.; Woolf, E. J.; Porras, A. G.; Chen, X.; Miller, N.; Michiels, M.; Wehling, A.; Schultz, A.; Gottlie, A. B.; Kraft, H. E.; Greenberg, S. A.; Waldman, S. P.; Curtis, S. P.; Gottesdiener, K. M.; J. Clin. Pharmacol. 2004, 44, 1125.

4. Agrawal, N. G. B.; Porras, A. G.; Matthews, C. Z.; Woolf, E. J.; Miller, J. L.; Mukhopadhyay, S.; Neu, D. C.; Gottesdiener, K. M.; J. Clin. Pharmacol. 2001, 41, 1106.

5. Agrawal, N. G. B.; Porras, A. G.; Matthews, C. Z.; Rose, M. J.; Woolf, E. J.; Musser, B. J.; Dynder, A. L.; Mazina, K. E.; Lasseter, K. C.; Hunt, T. L.; Schwartz, J. I.; McCrea, J. B.; Gottesdiener, K. M.; J. Clin. Pharmacol. $\mathbf{2 0 0 3}, 43,268$.

6. Dallob, A.; Hawkey, C.; Greenberg, H.; Wight, N.; De Schepper, P.; Waldman, S.; Wong, P.; Detora, L.; Gertz, B.; Agrawal, N.; Wagner, J.; Gottesdiener, K.; J. Clin. Pharmacol. 2003, 43, 573.

7. Matthews, C. Z.; Woolf, E. J.; Lin, L.; Fang, W.; Hsieh, J.; Ha, S.; Simpson, R.; Matuszewski, B. K.; J. Chromatogr., B: Anal. Technol. Biomed. Life Sci. 2001, 751, 237.

8. Rose, M. J.; Agrawal, N.; Woolf, E. J.; Matuszewski, B. K.; J. Pharm. Sci. 2002, 91, 405.

9. Bräutigam, L.; Nefflen, J. U.; Geisslinger, G.; J. Chromatogr., B: Anal. Technol. Biomed. Life Sci. 2003, 788, 309.

10. Werner, U.; Werner, D.; Hinz, B.; Lambrecht, C.; Brune, K.; Biomed. Chromatogr. 2005, 19, 113.

11. Ramakrishna, N. V. S.; Vishwottam, K. N.; Wishu, S.; Koteshwara, M.; J. Chromatogr, B: Anal. Technol. Biomed. Life Sci. 2005, 816, 215.

12. Brum Junior, L.; Fronza, M.; Ceni, D. C.; Barth, T.; Dalmora, S. L.; J. AOAC Int. 2006, 89, 1268.

13. Brum Junior, L.; Ceni, D. C.; Fronza, M.; Oliveira, P. R.; Dalmora, S. L.; J. Liq. Chromatogr. Relat. Technol. 2006, 29, 123.

14. Schellen, A.; Ooms, B.; van de Lagemaat, D.; Vreeken, R.; van Dongen, W. D.; J. Chromatogr., B: Anal. Technol. Biomed. Life Sci. 2003, 788, 251.

15. Gonçalves, J. C. S.; Monteiro, T. M.; Neves, C. S. M.; Gram, K. R. S.; Volpato, N. M.; Silva, V. A.; Caminha, R.; Gonçalves, M. R. B.; Santos, F. B.; Silveira, G. E.; Noel, F.; Ther. Drug Monit. 2005, 27, 601.

16. US Department of Health and Human Services, Food and Drug Administration, Center for Drug Evaluation and Research (CDER); Guidance for Industry, Bioanalytical Method Validation, 2001. 